International Journal of Education and Practice

2021 Vol. 9, No. 3, pp. 456-467.

$\operatorname{ISSN}(e): 2310-3868$

$\operatorname{ISSN}(p): 2311-6897$

DOI: 10.18488/journal.61.2021.93.456.467

(C) 2021 Conscientia Beam. All Rights Reserved.

check for
updates

\title{
EFFECTS OF AN INTERVENTIONAL MUSIC PROGRAM ON LEARNING SKILLS OF PRIMARY-SCHOOL STUDENTS WITH DYSLEXIA
}

\author{
Foteini \\ Bouloukou $^{1+}$ \\ Veronica Marin- \\ Diaz $^{2}$ \\ (iD) Noelia Jimenez- \\ Fanjul $^{s}$
}

\author{
'Department of Education, University of Cordoba, University of Cordoba, \\ Cordoba, Spain. \\ Email:ucobou@outlook.es Tel:+306976458739 \\ ${ }^{2}$ Didactics and Educational Organization, Department of Education, \\ University of Cordoba, Cordoba, Spain. \\ Email:vmarin@uco.es Tel: +34957212617 \\ ${ }^{s}$ Mathematics Education, Department of Mathematics, University of \\ Cordoba, Cordoba, Spain. \\ Email:noelia.jimenez@uco.es Tel:+34957218942
}

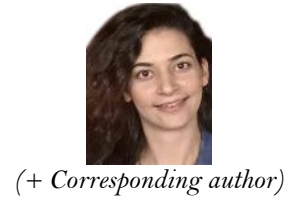

(+ Corresponding author)

\section{ABSTRACT}

\section{Article History}

Received: 19 February 2021 Revised: 24 March 2021 Accepted: 21 April 2021 Published: 17 May 2021

\section{Keywords}

Dyslexia

LAMDA test

Learning skills

Music intervention

Primary-school students

Rhythm perception.

\begin{abstract}
Research has shown that children with dyslexia have difficulties perceiving rhythm, and that musical training can enhance their learning skills. The purpose of this research was to investigate the effectiveness of an interventional music-training program based on rhythm-perception enhancement, within the curriculum of the music course in Greece. For this purpose, this research was conducted on primary school students over a period of 12 weeks. Thirty-two students of the 4th Elementary class, diagnosed with dyslexia, participated in the study. The LAMDA (Learning Skills and Weakness Detection Software) test, a weighted tool for automated detection of learning difficulties in written and oral language, was used to assess the improvement of children. The assessment showed that the interventional music-training program improved students' performance in areas such as word recognition, grammar spelling, visual sequences and rhythm reproduction. The research findings indicate that the incorporation of an appropriately adapted music program into the primary school curriculum, as well as the use of music as a systematic treatment, may have positive effects on students with dyslexia.
\end{abstract}

Contribution/Originality: This study contributes to the existing literature by highlighting the positive effect of an interventional music training program on the learning skills of students with dyslexia. The study identifies innovative musical activities adapted to the needs of students with dyslexia and employs the LAMDA test to assess the intervention's effects.

\section{INTRODUCTION}

Music offers students an opportunity for fun, but at the same time it can serve various educational purposes. Numerous studies highlight its positive effect on students' development, enhancing both their self-esteem and selfconfidence, and significantly improving their learning abilities, thus contributing to the development of their academic, social and linguistic skills. Music is a language that, despite its diversity, reduces learning barriers and individual peculiarities, allowing for experimentation and interaction (Sammler \& Elmer, 2020).

The relationship between music and learning disabilities is now widely accepted by the scientific community. It is a useful tool for occupational therapists, speech therapists and educators, which is why music is currently attracting more and more researchers to conduct research in the field of music therapy (Bonacina, Lanzi, Lorusso, \& 
Antonietti, 2015). The benefits that can result from music therapy for students with dyslexia include the stimulation of the brain (Schlaug, 2005), the enhancement of memory (Janata, 2009; Parbery-Clark, Skoe, Lam, \& Kraus, 2009), the triggering of motion at a specific pace, thus helping coordination (Corriveau \& Goswami, 2009; Slater, Tierney, \& Kraus, 2013), and the improvement of auditory skills (Frey et al., 2019; Putkinen, Tervaniemi, \& Huotilainen, 2013). Additionally, music listening and participation in musical activities lead to the enhancement of student's ability to split words, which is a process particularly difficult for dyslexics (François, Chobert, Besson, \& Schön, 2013). It also causes the strengthening of attention (Dewi, Rusmawati, \& Ratnaningsih, 2015; Putkinen et al., 2013; Tierney \& Kraus, 2013), the improvement of speech processing (Lifshitz-Ben-Basat \& Fostick, 2019; Patel, 2014), the possibility of boosting school performance (Slater et al., 2013), the production of chemicals (dopamine) in the brain that cause positive emotions (Salimpoor et al., 2013), and the empowerment of social skills (Gerry, Unrau, \& Trainor, 2012).

In recent years, researchers in the field of music, education and psychology have shown that music facilitates the overall development of the individual. More specifically, music education facilitates communication skills and, music therapy, in fact, allows the harmonization of interpersonal relationships between students with integration difficulties (Gooding, 2011; Ritblatt, Longstreth, Hokoda, Cannon, \& Weston, 2013). In addition, it is a privileged tool for the development of kinesthetic skills (Root-Bernstein, 2001), spatiotemporal skills (Crnčec, Wilson, \& Prior, 2006), perceptual and mental skills (Bidelman, Hutka, \& Moreno, 2013; Corrigall, Schellenberg, \& Misura, 2013; Kaviani, Mirbaha, Pournaseh, \& Sagan, 2014) and cognitive abilities, contributing to the improvement of their academic and school performance (Arnaud, Perlovsky, Bonniot-Cabanac, \& Cabanac, 2013).

Dyslexia is a disorder that tends to be associated with difficulties in developing reading and vocabulary skills, at the expected level of age and education provided. In recent years, the interest of a significant portion of researchers has been focused on examining the effect of music education on students with dyslexia. Reflecting the multidisciplinary interest in the broader dynamics of music, the discipline is increasingly used in a variety of everyday therapeutic, rehabilitative, medical, clinical, special education and community settings. Researchers are focusing on examining the broader implications of music-education programs in schools, leading to the creation of opportunities for all children to have equal access to such programs (Kraus \& Chandrasekaran, 2010).

Frey et al. (2019), taking into account the results of previous research on the positive effect of music on learning skills, compared music and painting intervention programs and their benefits to students with developmental dyslexia. The results showed that music education, compared to painting, had a positive effect on students with dyslexia. Furthermore, research shows a positive effect of music on the accuracy of reading, on the ability to read pseudo-words, on the speed of reading, as well as a significant improvement in the reproduction of the rhythm of the music (Goswami, Huss, Mead, Fosker, \& Verney, 2013; Huss, Verney, Fosker, Mead, \& Goswami, 2011). Going one step further, Przybylski et al. (2013) examined the effect of rhythm perception on editorial processing. They provided a rhythmic test to students with reading difficulties, followed by an oral phrase that was syntactically either correct or incorrect. The results clearly showed an improvement in editorial-work performance of students, with respect to both normal and irregular rhythmic patterns. Based on these results, the authors proposed the incorporation of rhythmic stimulations into the rehabilitation protocols designed for students with reading and writing disorders.

Habib et al. (2016) in their study on students with dyslexia, investigated the effectiveness of a new method of music intervention (“Cognitivo-Musical Training, CMT”), which included musical activities with special emphasis on rhythmic perception. They observed statistically significant improvements in auditory perception and attention, as well as in phonological awareness skills, reading skills and pseudo-word reading. A particularly important thing about this study was that the forementioned improvements remained six weeks after the completion of the program. Malak et al. (2017), using the "Tomatis" music-intervention method, explored which reading skills can be improved. The results showed that music training was highly correlated with phonological awareness skills, phonological and 
auditory short-term memory and selective attention, while a small correlation was found with respect to visual perception.

From the above, it can be seen that the use of music education for the rehabilitation of students with dyslexia and language disorders is based on both theoretical assessments and experimental results. If there are common underlying processes between music and language, especially between the perception of music and the perception of speech, it is reasonable to argue that improving some of the processes involved in the perception of music can simultaneously help improve reading and learning skills (Corrigall \& Trainor, 2011; Cumming, Wilson, Leong, Colling, \& Goswami, 2015; Frey et al., 2019; Lifshitz-Ben-Basat \& Fostick, 2019).

The purpose of this study was to investigate the effect of a music intervention program, based on rhythm reproduction activities, on learning skills of students with dyslexia. The study aims at identifying the level of improvement for each learning skill, according to the results of the LAMDA (Learning Skills and Weakness Detection Software) test and comparing the performance of students who attended the intervention music program with that of students who attended the conventional one.

\section{MATERIALS AND METHODS}

\subsection{Participants}

Thirty-two students, aged 8-9 years, attending the 4th Elementary class in Greece, participated in the study. Sixteen ( 8 females and 8 males) Greek-speaking students were classified as the control group and the remaining sixteen ( 8 females and 8 males) as the experimental group. All the students were from the same geographical area and from a similar socio-economic background. All participants had been diagnosed with dyslexia. The study commenced at the beginning of the school year, with all students having taken the same music education in the previous school years, with none of them having taken private lessons. The diagnosis of dyslexia was official and had been issued by a certified government agency. All the students had normal IQ of $>80$ and the study was conducted with the consent of the parents. No compensation was given for participation.

\subsection{Intervention}

The intervention program included rhythmic activities which were different from the ones that of the regular curriculum. More specifically, the music training was based on innovative multisensory, vocal, acoustic, kinesthetic activities, adapted to the needs of students with dyslexia. The rhythmic activities used aimed at improving memory, attention, concentration, the auditorial ability and the visual-spatial ability. All activities were designed to be enjoyable, without causing stress to students, with the aim of enhancing rhythmic perception and, by extension, as many skills as possible. The research tools employed for this purpose were the use of original, music-rhythm learning activities, based on popular methods such as those of Dalcroze (Dalcroze Society of America) and Orff.

Each lesson's duration was 40 minutes and the activities were divided into ten-minute thematic units, with the aim of verifying the motor, acoustic, visual-spatial ability. More specifically, adapted speech, movement, touch, hearing, pulse sensing activities were used to perceive the rhythm of the music. Indicatively, some of them are mentioned below:

- The teacher keeps the tempo of a song steady and asks each student individually to walk in rhythm while rhythmically bouncing a ball on the floor.

- The teacher hides a metronome in the classroom and students are asked to find it by its sound, while clapping to the rhythm.

- The teacher creates a path using large cards with musical values drawn on them, namely quarters and eighths. The students are asked to walk on it and at the same time hit a percussion instrument according to the value that is drawn on each card.

- The students imitate the shapes of rhythmic values using their bodies, upright or on the floor. 


\subsection{Assessment Test}

In order to evaluate the learning skills of students, the LAMDA test (Protopapas \& Skaloumbakas, 2008) was used. The Learning Skills and Weakness Detection Software (LAMDA) test was developed in the framework of the Business Program of Education and Initial Vocational Training (EPEAEK) of the Ministry of National Education and Religions by the IEL Institute of Speech Processing and is a software for the detection of learning difficulties within the general student population that attends the classes: (a) 2nd Elementary, (b) 3rd \& 4th Elementary, (c) 5 th \& 6th Elementary, and (d) 1st \& 2nd High School. This software detects potential specific learning difficulties. As Protopapas and Skaloumbakas (2008) point out, LAMDA examines skills that are indicators of learning potential and not measurements of school performance. The selected indicators are considered internationally reliable dimensions of learning assessment. All indicators constitute a complete criterion for investigating possible learning difficulties in oral and written speech for each age group.

The LAMDA tests directly assess the skills related to the learning potential and the corresponding performance of the student, providing immediately useful information about the areas of possible weaknesses of each student. The general skill areas assessed in LAMDA and the individual tests of each area are as follows: stimulus recognition (image recognition and word recognition), spelling (historical spelling and grammar spelling), comprehension of texts (oral comprehension, written comprehension, study of written text), syntactic (completion of proposals, proportions), vocabulary (image selection and definition of words), working memory (Letter range), non-verbal mental ability (visual sequences and completion of shapes) and perception of music characteristics (rhythm re-production).

The results of the automated LAMDA detection include the accuracy chart and the speed chart, which provide useful information either individually or in combination. Each diagram is a graphic representation of the student's performance in the LAMDA tests. Each row in the performance profile corresponds to a test. Students' performance is classified into 4 zones, compared to their classmates' performance. The intervals covered by the 4 zones are unequal, reflecting the degree of concern corresponding to each. Specifically, these are the intervals 0-10, 10-25, 2550 and 50-100 on the scale of percentiles. The performance profile of each student highlights the areas of potential weaknesses, which need further evaluation, and can be, if confirmed by the specialized examination, starting points of a learning intervention program. Any student with a performance that is significantly lower than expected for his/her class in two or more individual tests, or in one or more general areas of skills, should be referred for further investigation.

The assessment criteria of the LAMDA test are described below:

- Image Recognition: It refers to a selection response to a visual stimulus, in which the student must act quickly when a particular image is presented and suppress the reaction to any other image. The pictures are very different, so the only requirement from the student is prolonged attention. Low accuracy in this exercise can mean a lack of concentration.

- Word Recognition: It is a lexical selection test, in which the student must act quickly when a real word appears on the screen and suppress the reaction when a false word appears.

- Spelling (historical and grammar): A student's level of spelling depends on his/her general language experience and, in particular, on his/her writing experience. As the student's knowledge increases, spelling mistakes are reduced. It has been observed that under time pressure more spelling mistakes are made.

- Comprehension (written and oral): Comprehension of spoken language is a prerequisite for linguistic communication orally or in writing. At the same time, oral performance contributes to and influences the level of written comprehension. A student, as a rule, has a better performance in speaking than in writing. LAMDA detects the comprehension of oral speech in the form of narrative text and not the comprehension of the flowing, spontaneous oral speech that we use in our daily oral communication. Thus, the demands of speech processing are increased. Their structure gets more complex than spontaneous speech and it places additional demands on 
language processing. The written comprehension is examined in LAMDA with the presentation of a written text for the student to read. The text is then withdrawn, and image choices or multiple-choice questions are given, as in the oral comprehension test.

- Completion of sentences and verbal proportions: These are indicators of syntactic-processing abilities. In completion of sentences, the correct answer is limited by the phrasal context provided. Thus, the student is asked to complete a sentence with the appropriate word. In some questions, the alternatives differ in morphology and therefore it is to find out whether the type of word serves the necessary function within the particular phrase. The method of verbal proportions is used to test the student's ability in productive and clitic morphology, without a supporting phrase frame. This exercise requires the explicit morphological manipulation of words without useful consequences so it can be characterized as linguistic.

- Image selection: It includes one virtual speaker, who utters a word, while at the same time four images are displayed, of which only one successfully represents the spoken word. The student is asked to choose the right one, e.g., the word "appliance" refers to an ironing board (correct choice), a horn, a hermit crab and a high-pressure cylinder. Poor vocabulary can be an indicator of learning difficulties. On the contrary, a relatively rich vocabulary is important for a child's success in school.

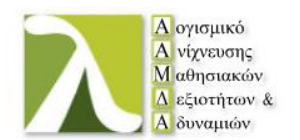

STUDENT ST1

\section{LAMDA Results}

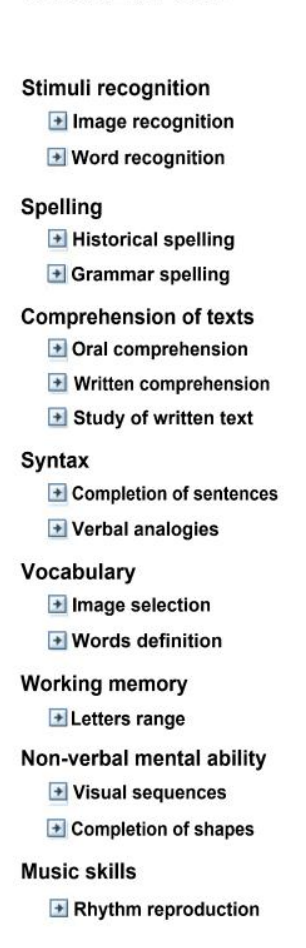

- In the accuracy chart, red denotes more errors than the $90 \%$ of classmates, yellow denotes more errors than the $75 \%$

- In the speed chart, red denotes slower than the $90 \%$ of classmates, yellow denotes slower than $75 \%$ of classmates.

Figure-1. Random assessment test (screenshot of the LAMDA test, tentatively translated into English by the authors).

- Letter range, visual sequences and pattern completion: This refers to working memory assessment by sequence playback. As with other learning disabilities software, LAMDA uses letter sequences rather than numbers, so that the exercise is more difficult for students with insufficient experience in processing written data. Only consonants are used to form the sequences, so that the letter sequences that the student has to memorize do not form words or syllables, which make them easier to memorize. Thus, the exercises examine the verbal working 
memory, which seems to be particularly weak in students with language learning difficulties. Pattern completion pertains to completing the missing parts of a given shape.

- Perception of music characteristics: The processes of perception of characteristics of music (rhythm, harmony, melody) are directly connected with corresponding processes of perception of characteristics of oral speech. In students with learning development and literacy disorders, the ability to reproduce musical rhythm is associated with learning ability.

\subsection{Procedure}

Participants attended weekly sessions of the interventional music program, over a 12-week period. All training sessions consisted of music activities customized to the needs of students, as described in section 2.2. Before and after the intervention, all the students took the LAMDA pre-test and post-test respectively, created by the Speech Processing Institute Department of Educational Technology (Protopapas \& Skaloumbakas, 2008).

\section{RESULTS}

The findings regarding the overall improvement (or lack thereof) in the performance of the dyslexic students comprising the experimental group are summarized in Figure 2. For each LAMDA-test criterion, the number of students with improved performance is represented by the horizontal bar next to it. Since the results of the LAMDA test classifies the students into four performance intervals, i.e., $0-10 \%, 11-25 \%, 26-50 \%, 51-100 \%$, the amount of improvement is denoted by different colors within each bar, based on the number of intervals by which this improvement occurred, e.g., for a student performing within the 0-10\% range in the pre-test, and within the 51$100 \%$ range in the post-test, an improvement by three intervals is reported.

The findings show that the intervention improved the performance of all 16 students in rhythm reproduction (for 11 of them by three intervals, for three of them by two intervals and for two of them by one interval), as well as in letter range (for nine of them by three intervals, for five of them by two intervals and for two of them by one interval), in visual sequences (for two of them by three intervals, for 11 of them by two intervals and for three of them by one interval), in word recognition (for ten of them by two intervals and for six of them by one interval), in image recognition (for seven of them by two intervals and for nine of them by one interval), and in pattern completion (for seven of them by two intervals and for nine of them by one interval).

In addition, 14 out of 16 students exhibited an improvement in historical spelling (five of them by two intervals and nine of them by one interval), and in image selection (all 14 by one interval). Moreover, 12 out of 16 students showed an improvement in grammar spelling (one of them by two intervals and 11 of them by one interval). A total of three students performed better in verbal proportions (all three of them by one interval) and only two students appeared to have improved in written comprehension and completion of sentences (all by one interval).

Finally, improvement was observed by none of the students regarding verbal comprehension. In Figure 3, the overall performance differences are presented similarly to Figure 1, this time based on the gender of the participating students. The overall improvement appears to be similar between male and female students.

Figure 4 presents the findings regarding the overall performance improvement of dyslexic students belonging to the control group. Similar to Figure 2, the different colors represent the number of intervals by which the improvement took place. The findings show that the conventional music lessons of the typical curriculum had a positive effect on 12 out of 16 students in in image recognition ( 8 of them by two intervals and 4 of them by one interval), rhythm reproduction ( 8 of them by two intervals and 4 of them by one interval), word recognition (six of them by two intervals and six of them by one interval) and pattern completion ( 5 of them by two intervals and 7 of them by one interval). 


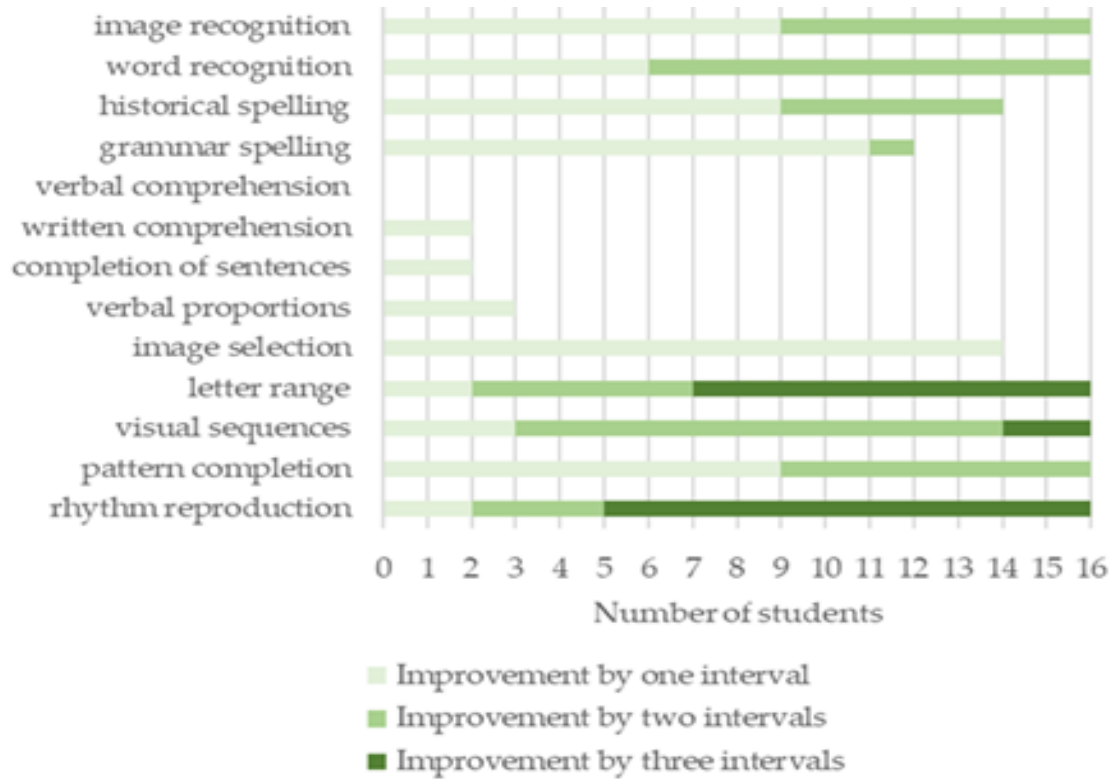

Figure-2. Number of students of the experimental group that improved in each LAMDA-test category.

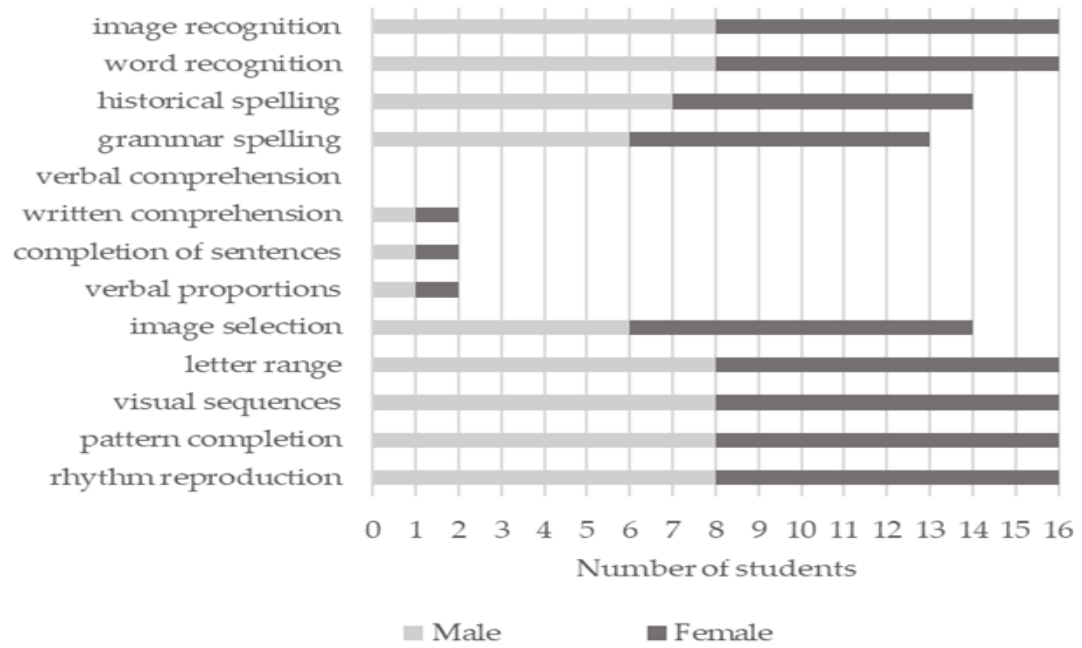

Figure-3. Number of male and female students of the experimental group that improved in each LAMDA-test category.

It also improved the performance of 11 students in letter range ( 5 of them by two intervals and 6 of them by one interval). For 10 students an improvement appeared with respect to visual sequences ( 4 of them by two intervals and 6 of them by one interval). Eight students performed better in image selection ( 3 of them by two intervals and 5 of them by one interval), while, for seven students, enhanced performance was exhibited in historical spelling ( 2 of them by two intervals and 5 of them by one interval) and grammar spelling ( 1 of them by two intervals and 6 of them by one interval).

No improvement was observed for any of the students of the control group in verbal comprehension, written comprehension, completion of sentences and verbal proportions. Finally, as can be observed in Figure 5, there are no significant differences in performance improvement between male and female students of the control group.

In Figure 6, the number of students that improved in each LAMDA-test category is presented for both the experimental and the control group, for comparison purposes. Compared to the music courses of the typical curriculum, the interventional music-training program appears to be considerably more beneficial with respect to rhythm-related skills, and consequently to all pertinent LAMDA-test criteria, namely image recognition, word recognition, historical spelling, grammar spelling, image selection, letter range, visual sequences, pattern 
completion and rhythm reproduction. On the other hand, the difference between the two groups is less profound regarding written comprehension, completion of sentences, verbal proportions and verbal comprehension. However, with the exception of the latter, even in those skills some improvement was observed in the case of the experimental group whereas none was detected in the case of the control group.
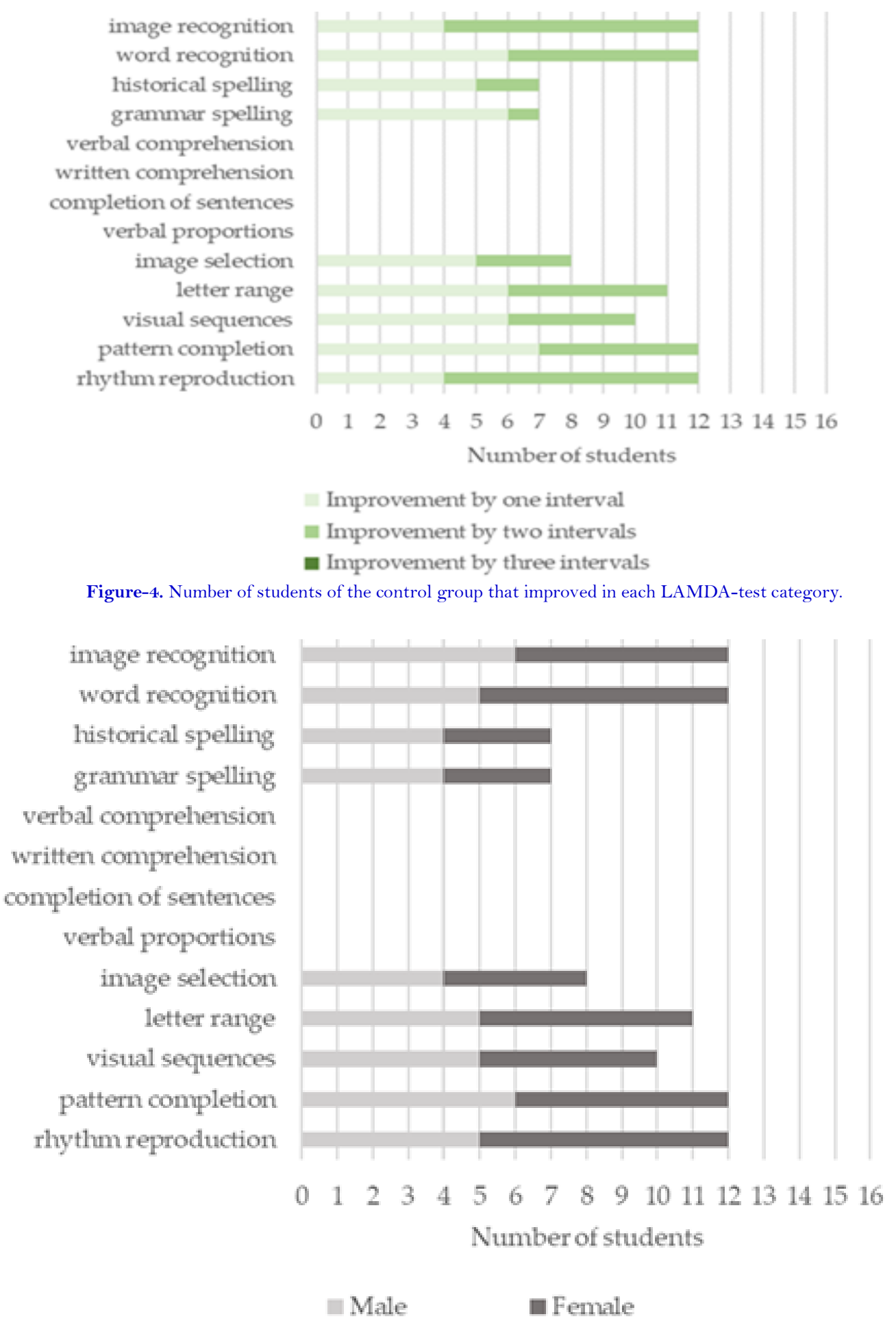

Figure-5. Number of male and female students of the control group that improved in each LAMDA-test category. 


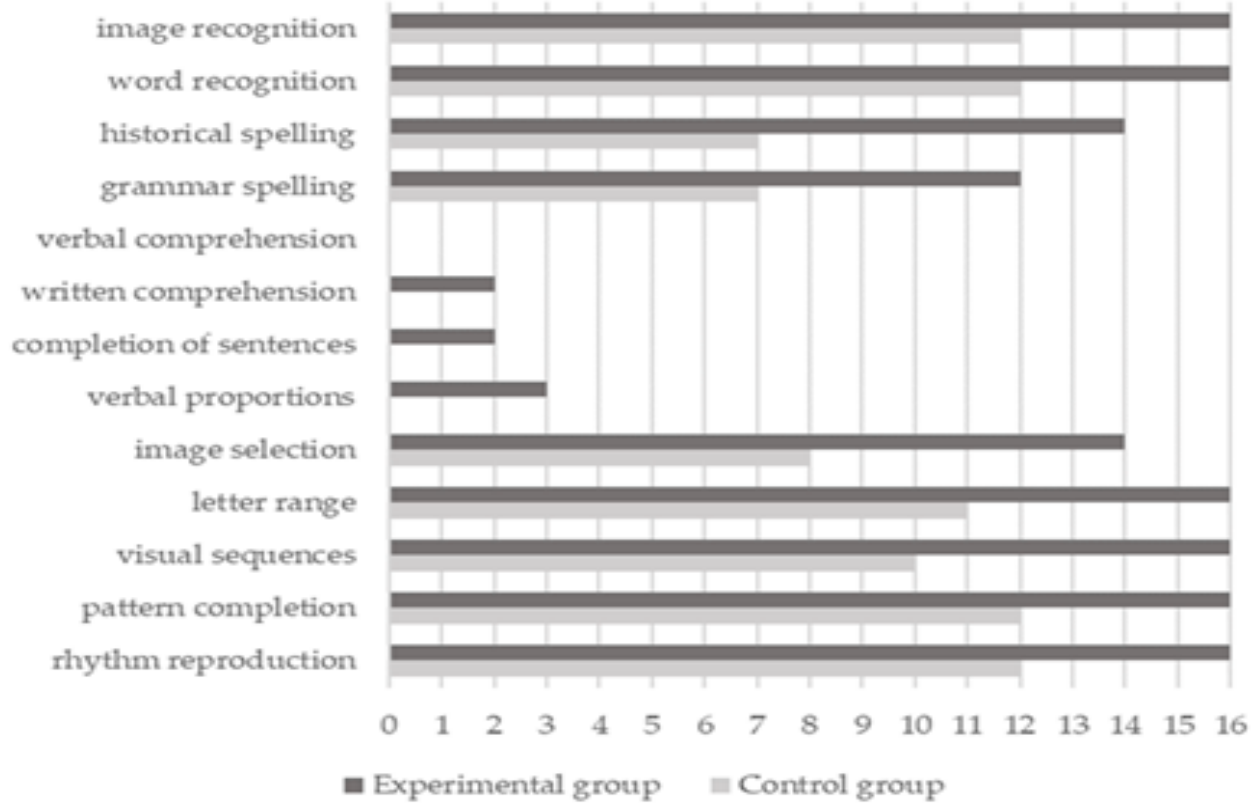

Figure-6. Comparison between the experimental and the control group with respect to the number of students that improved in each test category.

\section{DISCUSSION}

The activities carried out during this research were adapted to the needs of students with dyslexia. Performing musical activities is a complex process that requires the use of many different skills. More specifically, the improvement of memory and attention skills through the second activity described in section 2.2 and similar activities not only helped each child to develop its musical abilities but also to exhibit further improvement in the corresponding sections of the lambda test that concerned working memory and attention.

The first activity mentioned in section 2.2, which aimed at developing the ability of visual-motor coordination and synchronization with the rhythm, a skill typically deteriorated in case of students with dyslexia, proved to have positive effects on coordination of movement and rhythm and, hence, led to improved results in the LAMDA-test's image-recognition section. Moreover, the verbal pronunciation of pseudo-words in combination with rhythmic hand-clapping, foot-stamping and percussion are some of the activities that improved the rhythm perception and consequently the performance in the word-recognition section of the LAMDA test. The enhancement of imagerecognition and word-recognition skills as a result of improving rhythm perception of students with dyslexia agrees with the findings of Huss et al. (2011) and Goswami et al. (2013).

Additionally, the improved performance in image selection, letter range, visual sequences and pattern completion is directly related with the abilities of concentration and prolonged attention, as also demonstrated by Schlaug (2005) and Tierney and Kraus (2013). Finally, the enhanced performance in other LAMDA-test sections, such as grammar and historical spelling, written comprehension, completion of sentences and verbal proportions signifies a broader improvement in learning skills, as reported in the studies of Corrigall and Trainor (2011); Cumming et al. (2015); Lifshitz-Ben-Basat and Fostick (2019) and Frey et al. (2019). As far as the gender of the participating students is concerned, the results of the current research cannot sufficiently indicate whether this factor positively or negatively affects the effect of the intervention program on students with dyslexia.

\section{CONCLUSION}

The purpose of this study was to investigate whether the use of a music intervention program in the music course of the elementary-school curriculum could have a positive effect on learning skills of students with dyslexia. The program was based on activities that mainly enhanced the rhythmic skills of the students. Half of the thirtytwo students diagnosed with dyslexia who participated in the study attended the program. The LAMDA test 
results before and after the intervention were the means to evaluate the improvement of the students in various learning skills. The results of the research showed that, compared to the conventional music course, the intervention program had a stronger positive effect on stimulus-recognition abilities of students with dyslexia. Multisensory, kinetic and spatial activities seem to have helped students with dyslexia by improving the learning process, which became more effective, enjoyable and full of fun.

The characteristic difficulties of students with dyslexia are those of the perception of rhythm, the coordination of hands with eyes, as well as the sense of reciprocity and direction. The results show that the improvement in rhythmic perception is more pronounced on the students who attend the interventional music program, compared to those who follow the conventional one. In contrast, the results also reveal that the intervention program does not produce significant differences in areas such as verbal and written comprehension, and syntactical skills. The above supports the hypothesis of the beneficial effect of music training on reading and phonological skills and emphasizes the important role of rhythm in phonological perception and production.

Considering their positive impact on skills which are typically deteriorated by dyslexia, the activities of the interventional program would be a beneficial addition to the standard curriculum. Nevertheless, further research is needed in order for a larger student sample to be studied and more precise conclusions to be extracted.

Funding: This study received no specific financial support.

Competing Interests: The authors declare that they have no competing interests.

Acknowledgement: All authors contributed equally to the conception and design of the study.

\section{REFERENCES}

Arnaud, C., Perlovsky, L., Bonniot-Cabanac, M.-C., \& Cabanac, M. (2013). Music and academic performance. Behavioural Brain Research, 256, 257-260. Available at: https://doi.org/10.1016/j.bbr.2013.08.023.

Bidelman, G. M., Hutka, S., \& Moreno, S. (2013). Tone language speakers and musicians share enhanced perceptual and cognitive abilities for musical pitch: Evidence for bidirectionality between the domains of language and music. PloS one, 8(4), e60676. Available at: https://doi.org/10.1371/journal.pone.0060676.

Bonacina, S., Lanzi, P. L., Lorusso, M. L., \& Antonietti, A. (2015). Improving reading skills in students with dyslexia: The efficacy of a sublexical training with rhythmic background. Frontiers in Psychology, 6, 1510. Available at: https://doi.org/10.3389/fpsyg.2015.01510.

Corrigall, K. A., Schellenberg, E. G., \& Misura, N. M. (2013). Music training, cognition, and personality. Frontiers in Psychology, 4, 222. Available at: https://doi.org/10.3389/fpsyg.2013.00222.

Corrigall, K. A., \& Trainor, L. J. (2011). Associations between length of music training and reading skills in children. Music Perception: An Interdisciplinary Journal, 29(2), 147-155. Available at: https://doi.org/10.1525/mp.201 1.29.

Corriveau, K. H., \& Goswami, U. (2009). Rhythmic motor entrainment in children with speech and language impairments: Tapping to the beat. Cortex, 45(1), 119-130. Available at: https://doi.org/10.1016/j.cortex.2007.09.008.

Crnčec, R., Wilson, S. J., \& Prior, M. (2006). The cognitive and academic benefits of music to children: Facts and fiction. Educational Psychology, 26(4), 579-594. Available at: https://doi.org/10.1080/01443410500342542.

Cumming, R., Wilson, A., Leong, V., Colling, L. J., \& Goswami, U. (2015). Awareness of rhythm patterns in speech and music in children with specific language impairments. Frontiers in Human Neuroscience, 9, 672. Available at: https://doi.org/10.3389/fnhum.2015.00672

Dewi, E. K., Rusmawati, D., \& Ratnaningsih, I. Z. (2015). The effect of music and motoric movement intervention to increase attention among elementary school studentsin semarang central java. Procedia Environmental Sciences, 23, 179-185. Available at: https://doi.org/10.1016/j.proenv.2015.01.028.

François, C., Chobert, J., Besson, M., \& Schön, D. (2013). Music training for the development of speech segmentation. Cerebral Cortex, 23(9), 2038-2043. Available at: https://doi.org/10.1093/cercor/bhs 180. 
Frey, A., François, C., Chobert, J., Velay, J. L., Habib, M., \& Besson, M. (2019). Music training positively influences the preattentive perception of voice onset time in children with dyslexia: A longitudinal study. Brain Sciences, 9(4), 91. Available at: https://doi.org/10.3390/brainsci9040091.

Gerry, D., Unrau, A., \& Trainor, L. J. (2012). Active music classes in infancy enhance musical, communicative and social development. Developmental Science, 15(3), 398-407. Available at: https://doi.org/10.1111/j.1467-7687.2012.01142.x.

Gooding, L. F. (2011). The effect of a music therapy social skills training program on improving social competence in children and adolescents with social skills deficits. Journal of Music Therapy, 48(4), 440-462. Available at: https://doi.org/10.1093/jmt/48.4.440.

Goswami, U., Huss, M., Mead, N., Fosker, T., \& Verney, J. P. (2013). Perception of patterns of musical beat distribution in phonological developmental dyslexia: Significant longitudinal relations with word reading and reading comprehension. Cortex, 49(5), 1363-1376. Available at: https://doi.org/10.1016/j.cortex.2012.05.005.

Habib, M., Lardy, C., Desiles, T., Commeiras, C., Chobert, J., \& Besson, M. (2016). Music and dyslexia: A new musical training method to improve reading and related disorders. Frontiers in Psychology, 7, 26. Available at: https://doi.org/10.3389/fpsyg.2016.00026.

Huss, M., Verney, J. P., Fosker, T., Mead, N., \& Goswami, U. (2011). Music, rhythm, rise time perception and developmental dyslexia: Perception of musical meter predicts reading and phonology. Cortex; a Journal Devoted to the Study of the Nervous System and Behavior, 47(6), 674-689. Available at: https://doi.org/10.1016/j.cortex.2010.07.010.

Janata, P. (2009). The neural architecture of music-evoked autobiographical memories. Cerebral Cortex, 19(11), $2579-2594$. Available at: https://doi.org/10.1093/cercor/bhpoo8.

Kaviani, H., Mirbaha, H., Pournaseh, M., \& Sagan, O. (2014). Can music lessons increase the performance of preschool children in IQ tests? Cognitive Processing, 15(1), 77- 84. Available at: https://doi.org/10.1007/s10339-013-0574-0.

Kraus, N., \& Chandrasekaran, B. (2010). Music training for the development of auditory skills. Nature revierws. Neuroscience, $11(8)$, 599-605. Available at: https://doi.org/10.1038/nrn2882.

Lifshitz-Ben-Basat, A., \& Fostick, L. (2019). Music-related abilities among readers with dyslexia. Annals of Dyslexia, 69(3), $318-$ 334. Available at: https://doi.org/10.1007/s11881-019-00185-7.

Malak, R., Mojs, E., Ziarko, M., Wiechec, K., Sudol, A., \& Samborski, W. (2017). The role of tomatis sound therapy in the treatment of difficulties in reading in children with developmental dyslexia. Journal of Psychology and Cognition, 2(1), $17-20$.

Parbery-Clark, A., Skoe, E., Lam, C., \& Kraus, N. (2009). Musician enhancement for speech-in-noise. Ear and Hearing, 30(6), 653661. Available at: https://doi.org/10.1097/aud.obo13e3181b412e9.

Patel, A. D. (2014). Can nonlinguistic musical training change the way the brain processes speech? The expanded OPERA hypothesis. Hearing Research, 308, 98-108. Available at: https://doi.org/10.1016/j.heares.2013.08.011.

Protopapas, A., \& Skaloumbakas, C. (2008). Software for screening learning skills and difficulties (LAMDA). EPEAEK II Action, 1.

Przybylski, L., Bedoin, N., Krifi-Papoz, S., Herbillon, V., Roch, D., Léculier, L., \& Tillmann, B. (2013). Rhythmic auditory stimulation influences syntactic processing in children with developmental language disorders. Neuropsychology, 27(1), 121-131. Available at: https://doi.org/10.1037/a0031277.

Putkinen, V., Tervaniemi, M., \& Huotilainen, M. (2013). Informal musical activities are linked to auditory discrimination and attention in 2-3-year-old children: An event-related potential study. European Journal of Neuroscience, 37(4), 654-661. Available at: https://doi.org/10.1111/ejn.12049.

Ritblatt, S., Longstreth, S., Hokoda, A., Cannon, B.-N., \& Weston, J. (2013). Can music enhance school-readiness socioemotional skills? Journal of Research in Childhood Education, 27(3), 257-266. Available at: https://doi.org/10.1080/02568543.2013.796333.

Root-Bernstein, R. S. (2001). Music, creativity and scientific thinking. Leonardo, 34(1), 63-68. 
Salimpoor, V. N., van den Bosch, I., Kovacevic, N., McIntosh, A. R., Dagher, A., \& Zatorre, R. J. (2013). Interactions between the nucleus accumbens and auditory cortices predict music reward value. Science, 340(6129), 216-219. Available at: https://doi.org/10.1126/science.1231059.

Sammler, D., \& Elmer, S. (2020). Advances in the neurocognition of music and language. Brain Sciences, $10(8), 509$. Available at: https://doi.org/10.3390/brainsci10080509.

Schlaug, G. (2005). Effects of music training on the child's brain and cognitive development. Annals of the Nerw York Academy of Sciences, $1060(1), 219-230$.

Slater, J., Tierney, A., \& Kraus, N. (2013). At-risk elementary school children with one year of classroom music instruction are better at keeping a beat. PloS one, 8(10), e77250. Available at: https://doi.org/10.1371/journal.pone.0077250.

Tierney, A., \& Kraus, N. (2013). Music training for the development of reading skills. Progress in Brain Research, 207, $209-241$. Available at: https://doi.org/10.1016/b978-0-444-63327-9.00008-4.

Views and opinions expressed in this article are the views and opinions of the author(s), International Journal of Education and Practice shall not be responsible or answerable for any loss, damage or liability etc. caused in relation to/arising out of the use of the content. 